\title{
Implementing Curriculum Within a Context of Fear and Disengagement
}

\author{
Catherine D. Ennis, Donetta J. Cothran, Keren S. Davidson, \\ Susan J. Loftus, Lynn Owens, Lisa Swanson, and Peter Hopsicker \\ University of Maryland
}

\begin{abstract}
The purpose of this study was to examine situational and personal contextual factors that teachers and students reported as enhancing or minimizing student engagement in urban high school physical education classes. In this ethnographic study, 21 physical education teachers and their students in six high schools were observed, and all teachers at six schools and 51 students at five schools were interviewed to examine their perspectives on physical education. Data were analyzed using constant comparison. Findings suggested that students found some tasks to be embarrassing, boring, and irrelevant. Some students preferred to receive a failing grade rather than participate. All participants reported a sense of fear and alienation in the school or class environments. Students, however, described several teachers who created contexts of engagement in these schools. These teachers connected personally with students and worked to provide an innovative curriculum that students felt was relevant and worthwhile.
\end{abstract}

It is becoming increasingly apparent that the curricular programs and instructional methods traditionally used to plan and teach physical education in urban areas may not be providing programs that are meaningful to students (Ennis, 1995; Graham, 1995). These programs often assume that students value and are willing to learn traditional exercise and sport content taught in a teacher-controlled manner. This "business-as-usual" approach to physical education curriculum and teaching appears to be particularly unsuccessful in contexts in which students question the value of the educational process. These students report that education, itself, is not meaningful; that it does not lead to better job opportunities; and that who they are is not dependent on what formal or disciplinary knowledge they know (Brantlinger, 1991). In physical education, fewer urban students seem willing to "go through the motions" of dressing, completing jumping jacks and pushups, and participating in sport activities. They want programs in which the content connects to their lives and their interactions with teachers are satisfying and meaningful (Stinson, 1993).

Students who attend urban public schools report instances that suggest they suffer from poverty and neglect at home and are subject to intimidation, harassment,

The authors are with the Department of Kinesiology at the University of Maryland College Park, MD 20742-2611. 
and violence in their communities (Ennis \& McCauley, 1996). They often are low academic achievers who have concomitantly low expectations for life success (Brantlinger, 1991). Students are frequently victims of poorly designed curriculum and instruction in lower track programs. Page (1990) describes these programs as "games of chance" in which the content is trivialized, the tasks meaningless, and socially appropriate behavior is substituted for academic success. Learning in these settings requires students to endure classes that they describe as boring, irrelevant, and meaningless (Farrell, Peguero, Lindsey, \& White, 1988). Some students respond to these environments with disruptive and disengaged behaviors that make teaching more a contest of wills and personalities than an environment for learning (Ennis, 1996b). Effective teaching in urban schools over the next decade will require a much greater understanding of both the students themselves, and of the situational and personal school context. It will also require new forms of curriculum and the use of teaching styles that are more consistent with the manner in which these students live and learn (Ennis, 1996a).

The educational context in urban schools includes a multitude of factors that interact in complex ways to shape the educational environment (Talbert, McLaughlin, \& Rowan, 1993). Both social-situational and personal-subjective contextual factors influence the perceptions of participants within the educational process. Social or situational contexts involve factors beyond the individual's control that affect the learning process. These might include the economic funding available for education, the aspirations of one's peer group, and the level of safety or violence in the neighborhood (Campbell \& Ramey, 1995). Personal or subjective context refers to the beliefs, values, and attitudes that the individual brings to the school environment. Although these might be strongly influenced by friends or the community in which one lives, they are within the individual's conscious control. They strongly influence the extent to which aspects of the educational environment will be perceived as satisfactory, relevant, and meaningful (Ennis, 1996a).

There is increasing evidence that contextual factors directly influence the quality of the educational environment (Hannaway \& Talbert, 1993; Wells, Lipton, Hirshberg, \& Oakes, 1995). Purkey and Rutter (1987) compared urban and suburban teachers' reports of teaching conditions in schools to evaluate the climate or context conditions in a subset of schools in the High School and Beyond data set. They reported that students "encounter a less positive educational environment" and that teaching "is a more difficult task" in urban schools than in suburban schools (p. 388). In physical education, Ennis and Chen (1995) presented data to suggest that teachers in urban and rural schools demonstrate different educational value orientations. Urban teachers focused on more affective goals for student learning, while rural teachers placed a greater emphasis on goals oriented around subject matter.

In this study, our research team examined perceptions of physical education as viewed by teachers and students in six urban high schools. This paper presents data associated with contextual factors, while other papers have been presented to describe salient aspects of specific school settings (Cothran \& Ennis, 1996a, 1996b; Loftus \& Ennis, 1996; Owens \& Ennis, 1996a, 1996b). The purpose of this study was to examine the level of content acceptance by the students and to identify contextual factors, both positive and negative, that contributed to these perceptions. Further, we sought to move beyond reports of students' and teachers' "likes and dislikes" in physical education (although these were also examined) to study 
the social-situational and personal-subjective contexts that framed their perspectives. The research questions focused on aspects of context that school participants viewed as salient to the construction of their experiences in schools. Specifically, we asked, "Which aspects of the class environment were particularly disengaging for teachers and students?" and "Which aspects welcomed and invited participants to engage in teaching and learning?"

Studies of curriculum-in-context are important to our understanding of how students and teachers conceptualize and construct their experiences. More than simply a treatise on the popularity of a particular curriculum, studies such as these refocus our attention on students' and teachers' understandings of the curriculum and the class setting. They may provide the foundation for creating new, more meaningful forms of physical education curriculum that are more relevant for students and teachers within the complex, demanding environments in urban schools.

\section{Context}

The term context may be one of the most frequently used, but poorly understood, concepts within the educational literature. It is usually defined broadly to encompass most, if not all, of the physical, personnel, and material features existing in a school setting. The term context can be described as a theoretical construct that articulates dynamic relationships among "any of the diverse and multiple environments or conditions that intersect with the work of teachers and teachingsuch as the school, subject area, department, district, higher education, business alliance, professional networks, state policies, and community demographics" (Talbert et al., 1993, p. 46).

A more specialized conceptualization of the educational context construct may be found in the notion of context effects. Context effects are limited to the "influence of particular context conditions_-values, beliefs, norms, policies, structures, resources, and processes-on teaching practice and, in turn, students' educational outcomes" (Talbert et al., 1993, p. 46). The term implies the interactive and reciprocal nature of individuals' relations with their settings and the relevance of the coconstruction of teaching and learning outcomes in particular contexts. Studies of school context reveal complex relationships between situational and personal factors that influence students' opportunities to learn and their ability to focus on the learning environment.

\section{Situational Context}

Situational contextual factors reflect aspects of the physical environment that influence the extent to which students are exposed, can attend, and are encouraged to learn in school environments. There is evidence that situational contextual factors vary widely across different school districts. Policy analyses by Witte and Walsh (1990), for example, point to the relationships between effective school organization and the community context. They found that large clusters of social and organizational variables distinguish schools in urban and suburban communities. These situational contextual factors include parent socioeconomic status and involvement in schools, student achievement levels, and teacher control. They argue that these contextual variables interact to create "two very separate educational worlds, one in the city and one in the suburb" (p. 192). 
An additional factor that may act simultaneously as a social-situational contextual factor for students and a personal-subjective contextual factor for teachers is the way that "teachers think about their students" (Nieto, 1994, p. 395). It is critical that teachers believe that their students are deserving of opportunities to learn and, when presented with appropriate material, are capable of learning. Teachers' perspectives guide the level of effort they will expend and the insistence and encouragement that they are willing to invest in student learning. Nieto (1994) explains:

Educators may consider students difficult to teach simply because they come from families that do not fit neatly into what has been defined as "the mainstream." Some of them speak no English; many come from cultures that seem to be at odds with the dominant culture of U.S. society that is inevitably reflected in the school; others begin their schooling without the benefit of early experiences that could help prepare them for the cognitive demands they will face. (p. 394)

Students quickly become aware of limited expectations and conform and restructure their personal expectations to comply, demonstrating only those behaviors and skills that are called for within the class. As students demonstrate fewer abilities, teachers become increasingly frustrated and disassociated from the teaching process (Ennis, 1996b). Lucas, Henze, and Donato (1990) found that the most critical aspect of an effective school context is the shared belief among teachers, counselors, and administrators that all students are capable of learning. These commitments are critical to the success of all students and to the creation of environments in which students learn.

\section{Personal Context}

Students' and teachers' beliefs, values, and attitudes influence their perceptions of the context and their willingness to expend effort within the teachinglearning process. Students' individual perspectives on the learning context play an influential part in their willingness and ability to learn.

Research to examine personal or subjective contextual factors has focused on students' perspectives on their experiences in schools and classrooms. For instance, Nieto (1994) asked high school students from diverse cultures to reflect on school policies. She found that students perceived a cultural ambivalence that led them to question the value of their own ethnicity and inhibited their ability to fully connect with the educational messages of school. Moreover, they were particularly critical of what they described as the lack of teacher imagination that led to boring classes. They explained that it was difficult to continue to focus on the content when learning was such hard work. Interestingly, perceptions of ambivalence are unique to individual students. Although some students see a particular pedagogical practice as interesting and consistent with the way they want to learn, others complain that the practice is boring and irrelevant (Miller, Leinhardt, \& Sigmond, 1988).

Several studies in dance and physical education have focused on students' perceptions of the context. Stinson (1993) described how high school students encountered school and the differences they perceived between their experiences in their dance class and in other classes in the school. She concluded that students 
were asking for four things: (a) to be stimulated, to learn; (b) to have a sense of meaning in what they were being taught; (c) to be treated with understanding, to be cared for; and (d) to have the security and freedom to be themselves.

In physical education, a few efforts to understand the meaning that participants derive from high school physical education have provided insight into the often negative impact of secondary school practices (e.g., Figley, 1985; Tinning \& Fitzclarence, 1992). Carlson (1995) surveyed and interviewed high school students regarding feelings of alienation, such as lack of personal meaning, personal control, and isolation, in physical education. She concluded that alienated students found physical education activities irrelevant in their lives. They complained that class activities were too competitive. Carlson proposed an "alienationnonalienation" model that included both extrinsic (situational) factors and intrinsic (personal) factors. She pointed out that many of these factors were the result of outside influences that were beyond the control of the school and the teacher. Other factors, however, were specific to the curriculum and the instructional environment and could be altered by the teacher.

Some teachers and administrators appear to have difficulty responding positively and effectively to students' personal-subjective contexts. These unique factors influence what students personally perceive as interesting (e.g., Hidi, 1990; Tobias, 1994) or meaningful (e.g., Nieto, 1994) and may change as students experience new activities both in and outside of physical education. Students' diverse backgrounds suggest that their perceptions are also unique and specific to a particular set of experiences that each brings to the learning environment (LeSourd, 1990). Examinations of educational settings must be responsive to both situational and personal contexts. More than a contrived set of factors that are situated in the environment to entice or coerce students to learn, future efforts to reconstruct curriculum and instruction to be meaningful and intrinsically valued must begin with an in-depth understanding of the students' and teachers' interpretations of situational and personal contexts (Ennis, 1996a). This construct should be examined in relation to the daily factors that occur in the gym and the perspectives of teachers that are influential in creating and reforming contexts.

\section{Methods}

\section{Participants}

Twenty-one physical education teachers and their students at six different high schools in a large urban school district (student enrollment $>115,000 ; 70 \%$ African American) in the eastern United States agreed to participate in this research. Ten of the teachers were male, and 11 were female. Demographic data for teachers and interviewed students is reported in Table 1. Four of the teachers were in their first year of teaching; four had between 11 and 15 years of teaching experience, two had 16 to 25 , and 11 had over 25 years of teaching experience. Eight of the teachers were African American and 13 were White. Fifty-one students from five different high schools agreed to be interviewed about their experiences in physical education. Students at one school were not interviewed because of our inability to receive permission from the principal. Twenty-seven of the interviewed students were male, and 24 were female. Students represented Grades 9 to 12 , and the majority of the students $(n=38 ; 75 \%)$ were African American. 
Table1 Demographic Data for Teachers and Interviewed Students

\begin{tabular}{|c|c|c|c|c|c|c|c|c|c|c|c|c|c|c|c|c|c|c|}
\hline \multirow[b]{3}{*}{ High school } & \multicolumn{8}{|c|}{ Teachers } & \multicolumn{10}{|c|}{ Students } \\
\hline & \multicolumn{2}{|c|}{ Gender } & \multicolumn{2}{|c|}{ Ethnicity $^{\mathrm{a}}$} & \multicolumn{4}{|c|}{ Teaching experience $^{b}$} & \multicolumn{2}{|c|}{ Gender } & \multicolumn{4}{|c|}{ Ethnicity $^{\mathrm{a}}$} & \multicolumn{4}{|c|}{ Grade } \\
\hline & $\mathrm{M}$ & $\mathrm{F}$ & AA & $\mathrm{W}$ & $1-10$ & $11-15$ & $16-25$ & $>25$ & $\mathrm{M}$ & $\mathrm{F}$ & $\mathrm{AA}$ & $\mathrm{W}$ & $\mathrm{H}$ & Other & 9 & 10 & 11 & 12 \\
\hline Coleman & 2 & 1 & 0 & 3 & 0 & 0 & 0 & 3 & 6 & 4 & 10 & 0 & 0 & 0 & 2 & 2 & 3 & 3 \\
\hline Davenport & 1 & 2 & 2 & 1 & 2 & 1 & 0 & 0 & 6 & 4 & 9 & 1 & 0 & 0 & 1 & 1 & 3 & 5 \\
\hline Humbolt & 3 & 3 & 3 & 3 & 0 & 1 & 2 & 3 & 6 & 4 & 3 & 1 & 2 & 4 & 2 & 2 & 2 & 4 \\
\hline Littlefield & 1 & 2 & 2 & 1 & 1 & 2 & 0 & 0 & 4 & 12 & 15 & 1 & 0 & 0 & 4 & 3 & 3 & 6 \\
\hline Newman & 1 & 1 & 0 & 2 & 1 & 0 & 0 & 1 & 0 & 0 & 0 & 0 & 0 & 0 & 0 & 0 & 0 & 0 \\
\hline Pinehill & 2 & 2 & 1 & 3 & 0 & 0 & 0 & 4 & 5 & 0 & 1 & 4 & 0 & 0 & 0 & 3 & 0 & 2 \\
\hline Total & 10 & 11 & 8 & 13 & 4 & 4 & 2 & 11 & 27 & 24 & 38 & 7 & 2 & 4 & 9 & 11 & 11 & 20 \\
\hline
\end{tabular}

${ }^{\mathrm{a}} \mathrm{AA}=$ African American; $\mathrm{W}=$ White $\mathrm{H}=$ Hispanic.

bIn years. 


\section{Research Team}

Our research team consisted of one faculty member and six graduate students involved in collaborative research projects in urban public schools. Graduate students engaged in this project to gain experience and understanding of interpretive research paradigms and of the impact of the context of urban public schools on teachers' and students' beliefs and perceptions of physical education. Four researchers had extensive public and private school teaching experience, while three had never taught in public schools and brought fresh insights to our observations. Six researchers were pedagogists and one was a sociologist.

The faculty member on the research team acted as the research director, conceptualizing the research design and time line for data collection. She was responsible for site selection and entry into the school settings. She also facilitated team discussion and peer review sessions, addressed individual researcher's questions and concerns, and encouraged the team to reach consensus on research protocols when appropriate.

\section{Data Collection}

Data were collected weekly at each school from September to April. We began with an extensive observation period in which we familiarized ourselves with the schools and developed a rapport with teachers and students. We made an effort to identify and document the impact of personal and situational contextual variables on the teaching-learning environments. We met weekly as a team during the first weeks of the observation process to compare findings and to alert each other to specific contextual factors found at particular schools. As the school year progressed we met less frequently as a group. These later meetings focused on the development of interview formats and protocols for students and teachers. These meetings also were particularly important to identify negative cases and to focus on similarities across two or more research sites.

As the observation period continued, we tried to interact more frequently with teachers and students. We recorded informal conversations initiated by the teachers and students and gradually began to ask them to respond to our perceptions of situational and personal contextual factors. We began to glean from these conversations a better understanding of the referents that participants used to make decisions and evaluate the impact of these urban high school contexts on students' ability to learn and feel comfortable in physical education.

After 6 months of observation and informal conversations, we began to formally interview students in five of the six schools. We selected students to represent particular participant perspectives such as high, medium, and low ability and motivation; gender; and ethnicity. We used a structured interview guide format to ensure that each student was asked questions on topics that appeared relevant across schools. Students also were asked questions that were specific to their school or class based on the observation data collected. Interview questions focused on students' perceptions of physical education, beginning with likes and dislikes and moving on to feelings, impressions, and attitudes. We encouraged students to explain how physical education compared to other subjects in school and how it related to their lives outside of school. Each interview occurred during the student's regularly scheduled physical education class and lasted from 15 to 40 minutes. Interviews were audiotaped and transcribed for analysis. 
We interviewed each of the teachers at the conclusion of the student interviews. Interviews were scheduled during the teacher's planning period (approximately 50 minutes). Interview questions were based on the observations and the students' interview responses. We used a structured interview guide to ensure that the same topics were covered with each teacher. We also added additional questions that were specific to observations from each high school. We asked teachers about their beliefs about physical education and the aspects in the environment that they perceived facilitated or constrained their ability to teach. Moreover, we asked questions about student behavior and students' willingness to dress, participate, and learn in physical education. Teacher interviews were audiotaped and transcribed for analysis.

\section{Data Analysis}

Each researcher was responsible initially for the analysis of her or his own data. Data were analyzed using constant comparison (LeCompte \& Priessle, 1993). Data analysis occurred throughout the year, and the findings from each phase (i.e., observation, student interviews, and teacher interviews) were used to inform and focus the following phase. Data from each site were peer reviewed by other team members throughout the field work. At the conclusion of the field work, themes generated at each school were examined across each phase to compare the researcher's perspectives with those of the students and teachers. Additional comparisons were made across schools and teachers. Team members were responsible for the development and support of themes within their data and in the literature. The research director was responsible for synthesizing themes across high schools, querying researchers regarding negative cases, and conceptualizing the connecting themes across sites that provide the contrasts of engagement and disengagement presented in this paper.

\section{Findings: Characteristics of Disengaged and Engaged Contexts}

The purpose of this study was to examine the extent to which physical education content was accepted by students and to identify contextual factors that contributed to their perceptions. The six urban high school physical education programs that we examined required students to take one-half credit or one semester of daily, 50-minute physical education and permitted students to select from five different courses: team sports, individual sports, personal fitness, physical training, and dance. Team sports and physical training were selected primarily by boys, while girls enrolled in dance, personal fitness, and, to a lesser extent, individual sports. The team and individual sports programs were taught using primarily a multiactivity format.

In the team and individual sports classes, students received minimal instruction in the most basic skills (e.g., dribbling and passing in basketball, passing and setting in volleyball) and then engaged in game play for the remainder of the unit. Physical training consisted of weight training and running, while personal fitness included both cognitive and physical tasks. Dance was taught in three of the six schools and attracted high levels of interest from girls.

The teachers demonstrated a range of teaching abilities, interest, and effort in preparing and teaching their classes. Students also demonstrated a range of social and 
academically oriented behaviors, from the most cooperative and engaged to very disruptive and disengaged. The focus of this paper was the examination of situational and personal contextual factors that students and teachers perceived to promote disengagement and dissatisfaction and those that contributed to student engagement and enjoyment in the physical education learning process.

\section{The Situational and Personal Contexts of Disengagement}

Students in many of the observed physical education classes reflected negative feelings about the content and the class environment in physical education similar to those of the high school students in Carlson's (1995) research. Some of their concerns were associated with the "inconvenience" of participating in physical education, such as having to sweat or change clothes. There were other concerns associated with perceptions of a boring, repetitive, and irrelevant physical education curriculum that created a context of disengagement. Throughout all six schools, the context of school disengagement was fueled by fear and alienation. Students and teachers perceived the potential for violence that existed both inside and outside school. They reacted to this threat in ways that contributed to school and physical education disengagement and threatened the integrity of the school and the physical education programs.

The Embarrassing, Boring, Irrelevant Curriculum. Students in three of the six high schools, Littlefield, Davenport, and Pinehill (all names are pseudonyms), reported that physical education was embarrassing, boring, and irrelevant in their lives. Although they were given a choice of physical education classes, they found few that were stimulating or interesting. Several girls indicated that they were embarrassed to participate in front of others and complained that the boys often played "too rough" for their enjoyment. For example, Tara commented:

Some of the people [in my class] are scared to dress out. They're scared to be able to do stuff in front of people. So if they do dress out, they know they have to do the exercises and stuff. So they just don't bring their clothes and take the F.

Other students, such as Tammy, reported that they did not like the physical education content because they disliked sports. Tammy had enrolled in the team sports class because she had liked sports in her middle school physical education classes, but in high school she found that "playing games" was vastly different:

There's more boys than girls in class, well, more boys dress out anyways. Sometimes they're really rough. Like in handball, I was the goalie one time and the boys throw the ball at your head and not at the net. Boys are rough. They're okay to talk to in class, but I don't like to play with them.

Tamika agreed. She said that she had not wanted to take team sports, but it was the only course available when her schedule was arranged:

I don't really like sports, so I don't really like the games we play [in physical education]. I don't like to play in them so I don't like the class, because it's all playing games. The boys are too rough when you play, so I just don't play. Anyway, I don't like the games. 
Although some girls complained that the boys were too rough in team sports, others wanted more opportunities to play in more competitive games. Boys' aggressive play was intimidating to the point that some girls would rather receive a failing grade than have to participate with boys. Vertinsky (1992) points out that structuring classes using overtly coeducational formats does not always lead to equality. We have an extensive body of research that suggests that 25 years after the passage of Title IX, girls still do not have opportunities to participate equally in physical education (Ennis, 1995; Griffin, 1985; Wright, 1995). Our conversations with the four first-year teachers in these high schools suggested that, like the veteran teachers in this study, they had not been taught to create equitable environments. They felt that by simply changing the rules to accommodate girls' lack of strength and speed, they were doing their job to provide coeducational physical education.

Afrika reported additional concerns with the competitive team sport content and the locker room environment that made her not want to participate in physical education:

You're always doing stuff you don't even wanna do. Plus you've got to undress in front of strangers. . . . They be looking at you and stuff. You think, 'I take a shower in there?' [Shakes her head no.] Ugh, ugh, not me, no way with that open [shower] room.

Keith complained that the team sports classes repeated much of the same content that he had already experienced. He found physical education boring and repetitive:

Some of the sports, well, basically, most of them, we've been playing the same ways since elementary school. It's the same sports over and over, every school you go to. That's why I'm not interested in it much any more. It gets old playing the same thing over and over again. That's why I don't hardly get dressed much.

The physical education programs in these high schools permitted students to select which activities they preferred to take for both the required and the elective components of physical education. Some students, however, either did not give the selection process much thought or were required to take a particular course because there was little flexibility left in their schedule (e.g., physical education was one of the last courses scheduled). Further, it was evident that in some classes, such as personal fitness and physical training, boys and girls segregated themselves into what they considered gender-appropriate courses. Amanda explained that boys did not take personal fitness: “They think they don't need to get fit. They think they're a manly man who doesn't do girl aerobics. There's a lot of guys in physical training because muscles and stuff is more a guy thing than aerobics."

Other students focused on the lack of relevance of physical education to their lives outside of school. Allen said,

Teachers act like they are blind. . . . They don't know how to handle kids from the '90s. They're not like, you know, kids from the '70s. We have to adapt to this world, and it's real hard. Like now you have to worry about drive-by shootings. You have to worry about gangs; you have to worry about fights; you might get robbed. Now you have to worry about getting kid- 
napped and raped and being held hostage for 2 days or something. We have to adapt to how things are now. Teachers could tell us stuff that they learned when they were our age. They could talk to us like a friend and not like a teacher like most teachers act.

Many students at these three urban high schools appeared frustrated with the physical education program they were experiencing. They could both identify why they did not want to participate and what teachers could do to make it better. These students were different from those who talked with Farrell (Farrell et al., 1988) about the boredom and irrelevance they experienced in high school. Students in Farrell's study could give examples of boring classes, but could not define what the term "boring" meant to them. Students in this research described boring classes as those that repeated the same content year after year. Students perceived that they already knew how to play the sports, even though our observations suggested that they lacked the ability to perform many basic skills and performed others ineffectively.

Carlson (1995) found that content irrelevance or lack of personal meaning was a serious problem with high school students. It is not surprising that traditional sports and games curricula designed in the 1930s and revised and expanded in the 1950s and 1960s are not meeting the needs and stimulating the interests of urban high school students today. For example, skilled African American boys appear to play only basketball, while unskilled African Americans, both boys and girls, and students from other cultures who do not seem to value basketball, refuse to participate. Other team and individual sports are alien to their homes and communities (Harrison, 1995) and are seen as a punishment. Students would rather not participate than be embarrassed, humiliated, or harassed in these activities.

Teachers at Pinehill High School attributed the problem of student disengagement to laziness and lack of interest in sports other than basketball. Several teachers explained that they were required to teach a variety of team sports that students did not enjoy or relate to and that caused problems. Mr. Phillips said,

About 50 to 60 percent of the students at this school never get dressed. They just don't like having to play sports that they don't like. If we let them play basketball all the time, we would get $90 \%$ of them to participate.

The teachers at Pinehill appeared to be frustrated both with the number of students who rejected their curriculum and teaching and with the concomitant disruptive behaviors often displayed by these students. Rather than initiate changes to their curriculum and program policies, however, they used punitive means to penalize students who did not choose to dress and participate in their traditional sports, fitness, and physical training curricula:

Mr. Brown and Ms. Andrews moved around the gym after roll "collecting" all the students who had not dressed and took them to the Hole. The Hole was a small locker room adjacent to the gym that was poorly lighted and smelled like the old wrestling mats that were rolled up along the wall. Thirty to 40 students each period were herded into the Hole with one of the teachers assigned to stand in the door and prevent "talking and horsing around." The remaining teachers divided up the Hole supervisor's dressed students and included them in their own classes. Mr. Brown explained that this "was supposed to be a 
punishment and was the only thing we have found to stop these students from heckling the students who are willing to play." Ms. Andrews commented that the principals did not help them much with nondressers. They were on their own to deal with them while trying to run their classes.

These teachers were disconnected from their students. The curriculum was trivialized to the point that it did not matter which teacher's class a student attended. There was little content and no sequenced instruction, so students could join any of the other teacher's classes when their teacher took his or her turn guarding the Hole. The teachers created a situational and personal context that belittled students and appeared unconcerned about students' attempts to avoid these negative experiences. Mr. Jeffrey said:

I just tell the students what they want to hear. "You tell me you don't have your clothes today?" He picks up the phone and fakes dialing, "Yes, principal-I have a student here who will not be dressing. What? Okay." Then to the student, "Go to the office, the principal wants to see you." The student says, "All right, I'll dress."

Mr. Jeffrey continued to explain how they dissuaded students from playing basketball so they would participate in the multi-activity sport curriculum:

During the fall months of the year, we tell them we can't play basketball because the truck hasn't delivered the air for the balls yet. It works great. I just play on their ignorance. I believe that it is better not to argue and have a confrontation. As long as the students believe me, things go smoothly.

Although it would be nice to report that these teachers were close to retirement, they were not. Each had been teaching more than 20 years but saw their careers as extending 10 to 15 additional years. With relatively high salaries (most $>\$ 50,000)$, tenure, and a secure future, they saw no reason to change. They clearly did not take ownership of the problem of student boredom, embarrassment, or irrelevance, instead blaming the students for their unwillingness to dress or engage. In the case of Pinehill, students endured verbal abuse, teacher profanity, and regular trips to the Hole when they did not cooperate or participate. The alienation that occurred at this school was more extensive and devastating than any we have found reported in the literature.

Personal Contexts of Fear and Alienation. Teachers in every school reported difficulty enticing students to engage and participate in physical education. Students' dislike for physical education appeared to fuel negative behaviors, which in turn led some physical educators to use more punitive measures to control students and maintain a sense of order that they knew principals expected. Further, all schools employed extensive security systems to keep dangerous neighborhood individuals out of the schools and legitimate students in school and in their assigned classes. In physical education, students' dislike for the curriculum led two schools, Pinehill and Newman, to resort to locked gates and chained doors despite recent $\$ 4,000$ fines for fire code violations:

There was a locked metal gate at the foot of the stairs leading to the gym balcony where the weights were stored. The weight room wall overlooking the basketball court consisted of a three-foot high cinder block wall topped 
by fencing extending to the ceiling. The gate was locked after all students entered the weight room. Mr. Talbot explained to the researcher, "I have to lock them in to make sure they stay in class, and lock the other students out. If I didn't, half the boys in my classes would be down playing basketball."

Ms. Fletcher entered the gym. As she turned and locked a chain through the door handles, she explained, "It keeps the girls in the gym. If I leave the door open, they would just wander out." Another teacher reported that he also chained the doors to keep wandering students out of the gym. He reported that one time he left the doors unlocked while he left the gym. When he returned there were 50 students in the gym. He requested help from the administration, but they replied, "Deal with it." He shook his head and said, "If you haven't got the administrator's support, you haven't got anything."

The teachers reported that they felt isolated, detached, and at times afraid to teach in the school environment. They provided examples of the lack of adult control in schools. Ms. Morris at Littlefield explained:

It's like walking down the street. If you get a bad vibration or a sensation that something isn't right, then don't challenge it. If I end up in a confrontation in my class with a kid that I know by name then that's one thing-but if it's someone [in the hall] that I don't know, then that's another thing. They might not even be in this school as a student. When those situations arise, that's when I go to the little blue box in my room and call for an administrator or a security guard to come down here and deal with the situation.

After observing the administrators' attempts to maintain an orderly environment in the school lunch room, Ms. Morris at Littlefield laughed and said, "No way would I want to be an administrator. They' re like police without guns. That walkietalkie wouldn't help me much [if I had a real problem with a student.]" Just prior to an observation of a dance class at Littlefield, an administrator entered the room and asked everyone to leave. Ms. Morris angrily explained to the researcher that the administrator was going to conduct a strip search of a student found wandering in the hall, "In my room! During class! This place is a prison and they're using my room as the jail. It could be drugs or stolen stuff or weapons-you just never know."

On another day at Davenport High, the big news in the school that morning was the emergency faculty meeting called at 8:00 a.m. to discuss the arrest of two students for a murder the previous evening in the parking lot of the local mall. Ms. Mack later commented how "scary" this was for her as she tried to enforce school rules like "not loitering in the halls" or "not wearing hats or headphones." She said she realized how dangerous the students could be and that her job could be putting her life in jeopardy. On another day, Ms. Mack reported that a boy in her class was beaten on Thursday after school because he ignored the "requests" of several men in a large black car who drove up beside her playing field. They tried to coax the boy to leave her class and slip away with them. He refused to leave with them, so they followed him home after school and hit him in the face. He said they had told him, "Next time you better listen to us." Ms. Mack said with frustration:

It's the environment in the neighborhood that is brought into the school. It's their environment. It walked in here with them, and they are going to show 
it. They are going to show each other how intimidating they are, and it's such a battle, a territorial battle, when these kids walk in here. The peer pressure is phenomenal. And now I can look back and see what was happening [at the beginning of the year] when I say they were in my face. . . . It had so little to do with me. I think it is going to get more volatile as the years go on because the neighborhood is moving into this school. I don't mean the gangs ... I mean the poverty, the negligence, no support, no family. Nothing holding them together at home. They walk into my class and they have got to show the tough, defiant face they wear out there. So I'm going to be met with that same face they wear when they're meeting people who are being confrontational on the street. So they interpret my behavior to be equal to that and that in itself is incredible for a teacher to have to deal with.

Ms. Pollard, a first-year teacher at Davenport, also experienced feelings of violence and alienation that she felt were brought into her class by students not enrolled officially in her class. After one particularly confrontational episode, she said:

If the individual would have hit me, I would have hit back. I don't want to sound as violent as they do, but I think I would have gone to jail. Yes, I would have gone to jail. That's how angry [I was]. I guess it came from the beginning of the week and them not adhering to rules that were set at the beginning of the school year-opening doors [to let people into the gym] who don't belong here. It's just frustration upon frustration. And then after reprimanding him and sending him out [because he wasn't in my class], he decided that he wanted to confront me. And his way of confronting me was to walk up as if he was going to draw his fist to hit me. And my thing was, "God, please don't let him hit me because I'm goin' to jail tonight." [Because I would have hit him back.] I would not have allowed my husband to pay the bail to get me out either. I would have stayed there just for the fact that I would have gotten the appreciation ... ' cause [this student has] done it before but I kind of like overlooked it and walked away from it. That's my thing, I guess, motherly instinct, being a parent and knowing children. But this was more than even I can stand.

Later, Ms. Pollard explained:

Some of it, I sense, is a lot of peer pressure. Wanting to fit in and be liked. The reason I think that it's not totally a parenting problem is because of the parent conferences that I've gone to. All the parents have been very supportive and they want the same thing that I want for my own children.

Students also expressed fear and alienation within the school and in physical education. We asked Keesha what a student should do to fit in and be accepted at Littlefield High School. She focused more on protection of her property than social acceptance:

Don't put money or nice clothes in your locker. If people know something's in there that they want, they'll take it. Don't dress up too nice, like in leather coats and Coach bags and stuff like that, because people will take them. Be careful who your friends are 'cause friends turn on you if they're not true friends. Don't get in the wrong crowd because there's a lot of those here. 
Nicole also echoed these concerns when describing the atmosphere at Coleman High:

It's like sometimes walking down the hall. . . It's like when I look forward, I see all these people around me, and I just end up looking down at my feet because I don't want to look at nobody in the eye. I don't know why, it's just like that. . . .Worrying about if I'm going to get to school safe and get back home safe because of the things that go on around here.

Anthony also seemed confused and amazed at other's reactions at Davenport High:

People are basically crazy. They'll fight you over anything. They'll fight over people looking at them or talking to somebody. They're accusing people of stuff. It's stupid stuff. It doesn't have to be anything really. Like if you shoot the ball and [the rebound] hits somebody in the head, they're ready to fight. I mean, you didn't mean to hit them on purpose or nothing, but it don't matter.

We asked Raymond what students were afraid of at Littlefield. He said, "Just incidents that happened. Riots, fights, teachers getting shot. Stuff like that. They wondering if they next, could it happen again."

Each student and teacher with whom we talked was aware of the possibility of violence in their school building, the parking lot, or in their classes. They talked freely of their fears and the ways that their teaching had changed to build a safer environment for themselves and their students. Evidence is mounting to attest to the increasing incidences of violence in schools. The year prior to our study, a teacher had been shot at Littlefield. The National School Boards Association (1994) reported that in four out of five school districts, the problem of school violence is worse than it was 5 years ago, and $35 \%$ of school district administrators believe that school violence has increased significantly. Over $78 \%$ of the violence was student against student, $28 \%$ was student against teacher, and $61 \%$ involved weapons.

The comments of teachers and students in this study reflect a growing problem of community violence entering schools. The magnitude of this problem in some districts has led administrators to place a higher priority on stemming violence than in promoting academic programs (Noguera, 1995). In our six high schools, teachers were taking extreme measures to preserve their class environment, minimize stolen equipment, and keep their students safe. Some of the strategies they used, however, might well be contributing to violence rather than controlling it. Noguera (1995) argues that the fences, chains, and gates frequently found in urban high schools (including those in our study) lead to thinking of schools as prisons. This "get tough" policy is an overt response to the pervasive fear of violence felt by students, parents, teachers, and school officials. By locking down the gym and increasing penalties for violent talk, adults hope to regain control of situations that more closely resemble street corners than school corridors. Although these measures result in increases in suspensions and expulsions, they appear to have only a minimal influence on decreasing the perception of fear in these high schools (Noguera, 1995, p. 190-191).

\section{Personal Contexts of Engagement}

Although instances of violence and disengagement were present in each of our six high schools, there were three, Coleman, Davenport, and Humbolt, in which there existed small "pockets" of physical education teachers and students who were 
creating and experiencing contexts of engagement. These positive environments represented ethnographic negative cases in our research data. In these schools, the students possessed the same demographic characteristics as did the schools described above. A few teachers, however, worked to create a teaching and learning context that was physically and psychologically safe and personally relevant and meaningful for students. Students described a curriculum that was perceived to be interesting, even though the courses were the same ones taught at the other high schools. Moreover, they described teachers who took an interest in their lives and cared for them, and they, in turn, cared for these teachers. When asked what he was learning in his sport-education-based team sport class at Davenport, James explained:

I'm learning to deal with other people's attitudes and the way what they see is often different than the way I see it. I seen people getting along in different ways that they wouldn't if . . . I guess if Ms. Mack wasn't the teacher, because I've seen in different classes where they don't get along as well as they do in here. And I get a chance to help people because I'm like a coach [in sport education], and I get to help and see how people play and, you know, help them, and they can help me 'cause there's not a lot of things I know even though I do know how to play basketball.

Andrew, another Davenport student, explained the gradual changes that occurred in the sports education unit at Davenport:

Then there's other boys that don't like basketball at first [within the sport education framework], so they're not really into it, but they do it, you know, everybody does it to keep Ms. Mack happy, and eventually you see 'em smiling and having fun so it's not like they don't want to do it. They're just not used to doing it, so it takes some time to get used to it.

It took time for students to decide to participate in the sport education approach in Ms. Mack's class. The researcher asked William to comment on his experiences in the class, "So what's it like with Ms. Mack? Do you see disruptive kids?" He replied:

No, like I said before, she's strict, she's down. She's more down to earth. She doesn't play around. She's more serious, always goes by the rules, always tells us what's up and how far to push her-which isn't far. And she's real good. Like I said, she talks to us, she helps us out.

Interviews with Ms. Mack indicated that she was aware of the influence that she had on her students. However, she also realized that her ability to connect with them was based on particular behaviors and developing a specific rapport with her students:

They even liked knowing that I was going to call them on walking into the gym when they don't belong there-loitering. They even liked the consistency in that. If I did it to someone else, they wanna see it done to other people. They look for favoritism. They look for things that will prove to them that, "She cannot be trusted," and they are so vigilant in looking for that, I have to constantly be on my toes. You're thinking about a lot more than teaching here. How is this kid interpreting what I'm saying? How's this kid reacting to my walk, my 
talk, ... whether I'm up. I usually have a lot of energy. But, my energy can actually insult some kids. They hate it. It's uncomfortable for them. It's something that is foreign. They don't experience that at home. You know, so many things come into play. It is such a psychological game.

Interviews with Mr. Davis' students at Humbolt High indicated that he, too, was well respected by his students. Jordan said:

You don't have to say anything and he come to you to help you out. He likes to talk to me. You know, he likes to let me know something. Some teachers don't care what you do-you know what I'm saying? But with him, he stands there to see what you doing. If you're lifting a 100 pounds, he tell you, "You can do better than that." He says, "Go, go, go, you can do it." That's somebody who cares for you; who wants you to do something for yourself. Sometimes I know I drive him crazy, but he's my favorite teacher you know.

Students at Coleman High also felt that they were connected with the school and their physical education teachers. Jovaughn explained:

I think maybe because this is a small school, it makes a bit of difference because like the teachers can kind of work with the students on a one-on-one basis. I feel like I know a really lot of people here. OK, I feel very safe here. All the people I know don't bring weapons and stuff like that. I feel safe here. I feel very safe.

Terry explained the focus of his physical education class with Ms. Hardy:

I think, you know-working together as a team and working together with people you don't really know-if you come in and like, in volleyball, have to work with people you don't know, you have to cooperate with people you have never worked with before, you have to work as a team to win. If you try to do it by yourself, you are not going to accomplish it. Coleman:

Mr. Atkins explained the "sense of school" that students and teachers felt at

I think that it's really good that this school is smaller than other schools. There is more personalization-you know everybody. In this school, I won't have every child in class during their four-year time, but I will know every child in this building, even if I don't know them by name. I know them by face enough to speak to them in the hallway, and I know they belong and they know I belong here. I don't live far from Coleman, so I even see these same kids in the shopping centers. I think it's more of a family atmosphereit's a oneness-it's small. A lot of the teachers, too, have been here a long time and they've enjoyed this school and this community. It carries over into physical education-into every unit that we teach.

In contexts that promoted engagement, teachers treated students humanely and equitably, expressing concern and interest in them. The teachers at Coleman appreciated the small size and community feeling of the school that permitted them to connect with their students. Ms. Mack's team sports class was revitalized 
by the sport education curriculum (Siedentop, 1994) in which students took ownership and responsibility for learning skills and which included all students as equal and valued participants. Students, in turn, responded to the effort and concern expressed by teachers by reciprocating with cooperation and respect for the teacher. Although Ms. Mack was considered "a friend" whom you could talk to, she was also perceived as strict and businesslike. Students acknowledged that she took responsibility for creating a learning environment and continued to pursue these goals in the face of fear and alienating contexts that distracted other teachers from educational goals.

Students in these schools seem to respond as Stinson's (1993) students had. They connected and engaged in physical education when teachers worked to stimulate them to enjoy and appreciate learning. They perceived a sense of meaning in schools when teachers took an active interest in them as individuals and worked to present interesting and innovative content that was not seen as "the same old things." Finally, they responded positively when they felt physically and psychologically safe in class. To be sure, even Ms. Mack, Ms. Hardy, Mr. Atkins, and Mr. Davis reported that students resisted their approach at first, but they gradually convinced most students to connect and engage in their physical education program.

Although teacher preparation programs prepare teachers to create positive learning environments, rarely do they discuss issues of fear, alienation, and violence. Liston and Zeichner (1990) encourage teacher educators to open dialogues with preservice teachers regarding these "real world" problems and begin to assist them to analyze the sources of these problems and work proactively to minimize and prevent them in their classes. From our research, it appears quite easy to create situational and personal contexts of disengagement in schools and far more difficult to combat the feelings of embarrassment, boredom, and irrelevance that urban youths experience in school programs.

The pervasive sense of fear that all individuals in these urban schools experienced is deep and compelling. It is not something to be dismissed or brushed aside. Effective programs must provide opportunities for disenfranchised students to take ownership of the content within structured environments that are as safe as we can make them. An essential element in this formula is a curriculum that is culturally responsive, one that invites students to participate in curriculum that has meaning for them both in and out of school (Ladson-Billings, 1995).

Engaging curriculum and teaching require far more work and sacrifice than many teachers appear willing or able to give. Yet, these efforts appear essential to combat the difficult environments that students live with and bring to school. The development of situational and personal contexts that are engaging and meaningful is essential for all students. Further, it becomes a matter of survival for students who live in communities that are wracked with fear and alienation. Without reasons to engage in education in their community, this generation of urban students may have little chance for personally satisfying lives. Nor will they experience the opportunity to become productive members of society who are capable of reaching out and helping others to engage.

\section{References}

Brantlinger, E. (1991). Low income adolescents' perceptions of social class related peer affiliations in school. Interchange, 22, 9-27. 
Campbell, F.A., \& Ramey, C.T. (1995). Increasing the academic successes of disadvantaged children: An examination of alternative early intervention programs. American Educational Research Journal, 32, 743-772.

Carlson, T.B. (1995). We hate gym: Student alienation from physical education. Journal of Teaching in Physical Education, 14, 467-477.

Cothran, D.J., \& Ennis, C.D. (1996a, April). Dissimilarity of teacher and student perspectives of meaningful learning experiences. Paper presented at the annual meeting of the American Alliance for Health, Physical Education, Recreation and Dance, Atlanta, GA.

Cothran, D.J., \& Ennis, C.D. (1996b, April). "Nobody said nothing about learning stuff”: High school students' perceptions of physical education. Paper presented at the annual meeting of the American Educational Research Association, New York.

Ennis, C.D. (1995). Teachers' responses to noncompliant students: The realities and consequences of a negotiated curriculum. Teaching and Teacher Education, 11, 445-460.

Ennis, C.D. (1996a). A model describing the influence of values and context on student learning. In S.J. Silverman \& C.D. Ennis (Eds.), Student learning in physical education: Applying research to enhance instruction (pp. 127-148). Champaign, IL: Human Kinetics.

Ennis, C.D. (1996b). When avoiding confrontation leads to avoiding content: Disruptive students' impact on curriculum. Journal of Curriculum and Supervision, 11, 145-162.

Ennis, C.D., \& Chen, A. (1995). Teachers' value orientations in rural and urban settings. Research Quarterly for Exercise and Sport, 66, 41-50.

Ennis, C.D., \& McCauley, M.T. (1996, April). Disruptive students' rationales for their class behaviors. Paper presented at the annual meeting of the American Educational Research Association, New York.

Farrell, E., Peguero, G., Lindsey, R., \& White, R. (1988). Giving voice to high school students: Pressure and boredom, Ya know what I'm sayin'? American Educational Research Journal, 25, 489-502.

Figley, G.E. (1985). Determinants of attitudes towards physical education. Journal of Teaching in Physical Education, 4, 229-240.

Graham, G. (1995). Physical education through students' eyes and in students' voices. Journal of Teaching in Physical Education, 14, 364-482.

Griffin, P.S. (1985). Teachers' perceptions of and responses to sex equity problems in a middle school physical education program. Research Quarterly for Exercise and Sport, 56, 103-110.

Hannaway, J., \& Talbert, J.E. (1993). Bringing context into effective schools research: Urban-suburban differences. Educational Administration Quarterly, 29, 164-186.

Harrison, L., Jr. (1995). African Americans: Race as a self-schema affecting physical activity choices. Quest, 47, 7-18.

Hidi, S. (1990). Interest and its contribution as a mental resource for learning. Review of Educational Research, 60, 549-571.

Ladson-Billings, G. (1995). Toward a culturally relevant pedagogy. American Educational Research Journal, 32, 465-492.

LeCompte, M., \& Priessle, J. (1993). Ethnography and qualitative design in educational research. New York: Academic Press.

LeSourd, S.J. (1990). Curriculum development and cultural context. The Educational Forum, 54, 205-216.

Liston, D.P., \& Zeichner, K.M. (1990). Teacher education and the social context of schooling: Issues for curriculum development. American Educational Research Journal, 27, 610- 638 . 
Loftus, S.J., \& Ennis, C.D. (1996). Teachers' influences on students' involvement and participation patterns in physical education. Paper presented at the annual meeting of the American Alliance for Health, Physical Education, Recreation and Dance, Atlanta, GA.

Lucas, T., Henze, R., \& Donato, R. (1990). Promoting the success of Latin language-minority students: An exploratory study of six high schools. Harvard Educational Review, 60, 315-340.

Miller, S.E., Leinhardt, G., \& Sigmond, N. (1988). Influencing engagement through accommodation: An ethnographic study of at-risk students. American Educational Research Journal, 25, 465-488.

National School Boards Association. (1994). Violence in the schools. Alexandria, VA: Author.

Nieto, S. (1994). Lessons from students on creating a chance to dream. Harvard Educational Review, 64, 392-426.

Noguera, P.A. (1995). Preventing and producing violence: A critical analysis of responses to school violence. Harvard Educational Review, 6, 189-212.

Owens, L., \& Ennis, C.D. (1996a, April). The ethic of care in an urban high school. Paper presented at the annual meeting of the American Alliance for Health, Physical Education, Recreation and Dance, Atlanta, GA.

Owens, L., \& Ennis, C.D. (1996b, April). Feminist perspectives on high school physical education: Conceptualizing curriculum from an ethic of caring. Paper presented at the annual meeting of the American Educational Research Association, New York.

Page, R.N. (1990). Games of chance: The lower track curriculum in a college-preparatory high school. Curriculum Inquiry, 20, 249-281.

Purkey, S.C., \& Rutter, R.A. (1987). High school teaching: Teacher practices and beliefs in urban and suburban public schools. Educational Policy, 1, 375-393.

Siedentop, D. (Ed.) (1994). Sport education: Quality physical education through positive sport experiences. Champaign, IL: Human Kinetics.

Stinson, S.W. (1993). Meaning and value: Reflections on what students say about school. Journal of Curriculum and Supervision, 8, 216-238.

Talbert, J.E., McLaughlin, M.W., \& Rowan, B. (1993). Understanding context effects on secondary school teaching. Teachers College Record, 95, 45-68.

Tinning, R., \& Fitzclarence, L. (1992). Postmodern youth culture and the crisis in Australian secondary school physical education. Quest, 42, 287-303.

Tobias, S. (1994). Interest, prior knowledge, and learning. Review of Educational Research, 64, 37-54.

Vertinsky, P.A. (1992). Reclaiming space, revisioning the body: In quest of a gender-sensitive physical education. Quest, 44, 373-396.

Wells, A.S., Lipton, M., Hirshberg, D., \& Oakes, J. (1995). Bounding the case within its context: A constructivist approach to studying detracking reform. Educational Researcher, 24(5), 18-24.

Witte, J.F., \& Walsh, D.J. (1990). A systematic test of the effective schools model. Educational Evaluation and Policy Analysis, 12, 188-212.

Wright, J. (1995). A feminist poststructuralist methodology for the study of gender construction in physical education: Descriptions of a study. Journal of Teaching in Physical Education, 15, 1-24. 